\title{
Producing a Dissimilar Joint of Copper to Austenitic Stainless Steel by Ultrasonic Welding
}

\author{
Schramkó Márton, ${ }^{1}$ Kovács Tünde Anna ${ }^{2}$ \\ 1,2 Óbuda University, Donát Bánki Faculty of Mechanical and Safety Engineering, Budapest, Hungary, , \\ Budapest, Hungary, kovacs.tunde@uni-obuda.hu
}

\begin{abstract}
There are several possibilities for establishing a cohesion joint between dissimilar metals. In the case of thin sheets, the ultrasonic welding process is suitable. This process can establish a cohesion joint rapidly, with a low heat input between the thin sheets. The authors have tried to determine the optimal ultrasonic welding parameters for copper and austenite stainless steel joining by using an experimental method of joining. Suitable results were obtained by welding tests due dissimilarities in the chemical, physical and mechanical properties of the copper and stainless steel. A standard size sheet thickness and test sample was used for the welding by different parameters. The parameters were refined based on the theoretical and practical knowledge during the experiments. The experimental welding was made by a Branson L20 type welder machine. The joint made by the different parameters was inspected by shearing-tensile tests (maximal force level).
\end{abstract}

Keywords: ultrasonic welding, copper, stainless steel.

\section{Introduction}

The industry is facing new challenges in bonding technology. Low heat input processes are not only evolving in the field of fusion welding but are increasingly used in compression welding processes or soldering to join thin sheets [1, 2]. Ultrasonic welding is a process that produces a low heat input cold press welding process that creates a cohesive bond without the use of added welding consumables. The procedure is very simple if the welding parameters have been optimized, the operator does not have to be a qualified welder, it is a task that can be performed by a trained worker. In addition, the typical welding hazards (spattering, smoke, heat) are considerably lower. Of course, it is necessary to protect the operator's hearing against the effects of ultrasound.

The beginnings of ultrasonic welding date back to Pierre Curie, a professor of physics and chemistry who discovered the relationship between electrical voltage and pressure in 1881 during the study of crystalline materials [3]. He worked as an assistant in the physics laboratory at the Sorbonne University in Paris from an early age. He devoted his doctoral years to crystallogra- phy, within which he dealt with the problem of the distribution of crystalline materials, which he studied on the basis of the law of symmetry. He received his doctorate in 1895. Together with his brother Jaque Curie, they supported the existence of piezoelectricity and the name comes from them. This discovery was the cornerstone of the development and then the widespread of modern ultrasonic energy converters and ultrasonic welding [3].

Dr George Ludwig, a researcher at the University of Pennsylvania, studied and recorded the change in direction of sound waves in 1940 through different parts of the body. He spent most of his time on the detection and non-destructive examination of gallstones in the human body. As a result of its successful results, an ultrasound examination was born, and which is still used in many areas in the field of medical science to this day. The principle of this is the same as in non-destructive material testing used in industry, the technology is mostly used in practice for the inspection of welded joints.

In 1960, technology began to spread in the industrial environment. Robert Soloff during his time 
as laboratory manager at Branson Instruments, who were involved in welding plastic films together into bags. One day, the welding probe accidentally touched the plastic strip dispenser and formed a bond. It was then that Soloff realized that ultrasound was able to cross and propagate in solids as well, and thus was able to weld different materials together. In 1969, the first car made of plastic material was created using this technology by a company called Sonics \& Materials, founded by Robert Soloff. In reality, the small car wasn't a big hit, but the technology it was based on took its first step to become viable, hence they started to explore its potential. Although this product has not enjoyed undivided success, the factory has been operating successfully to this day and has been engaged in ultra-sonic welding ever since.

During ultrasonic welding, the surfaces are subjected to low pressure, during which the vibrational motion caused by the ultrasound destroys the roughness protrusions of the welded surfaces and the oxide layers, thereby rubbing the metallic surfaces together to form the bond. The huge advantage of this operation is that no heat has to be transmitted from the outside to the workpiece so that deformations due to heat shock can be avoided. It is excellent for welding plastics, steels and other metals, with some exceptions, for example, fatigue cracking can occur quickly with too hard materials, whereas well-formed and high damping materials can be welded well [4].

Another advantage of the process is that the effect on the environment is very minimal, no harmful waste is generated by the technology.

\section{Ultrasonic welding}

This method of welding is very interesting since it produces vibrations from an electric current,

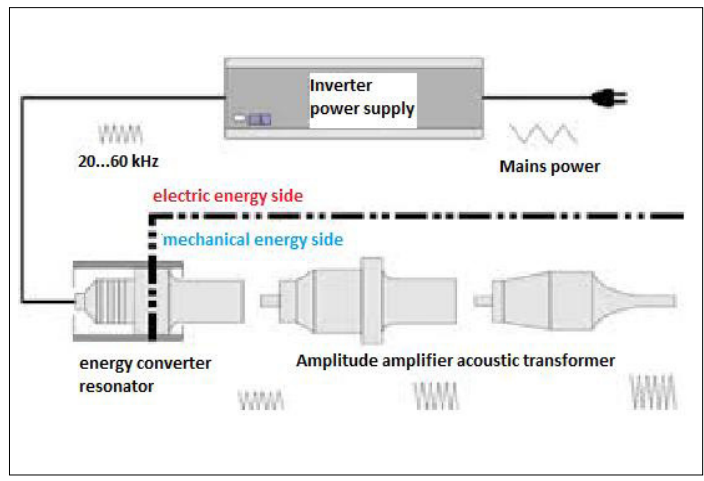

Figure 1. Schematic illustration of a spot welder. [1] which vibrates the workpiece through the welding head (Sonotrode). This effect, as well as the compressive force, results in the welding itself. There is no high heat zone during the process, and it can be used as both spot welding and line welding. The process is time consuming, for example 0.5-2 seconds for spot welding. The technology makes it easy to weld between different materials, but unfortunately only high formability, non-brittle materials are suitable for the technology. It is important that the wall thickness of the workpiece is not large, as welding can be used for plate thicknesses between 0.5 and $1.5 \mathrm{~mm}$. Therefore, the experiments were performed with these parameters in mind [5].

The device operates on the principle of electrostrictive or core-netostriction (Figure 1).

Ultrasonic welding machines have two major groups of line and spot welders. The principle of these is almost identical. The main difference is that in the case of a line welder, the sound-producing and transmission members can all be rotated, as can the sonotrode and the seat. The ultrasonic spot welder is externally similar to the resistance welder (Figure 2). The pieces to be machined are located between the sonotrode and the anvil of the machine. The clamping pressure is generated by hydraulic or pneumatic machinery.

\section{Materials and methods}

Welding together austenitic stainless steel and copper is not an easy task due to their different physical-chemical and mechanical properties. The optimization of the ultrasonic welding parameters of copper-copper and austenitic stainless steel has already been optimised in preliminary experiments.

In our experiments, two materials were used: a stainless steel plate, and a $99.5 \%$ pure copper

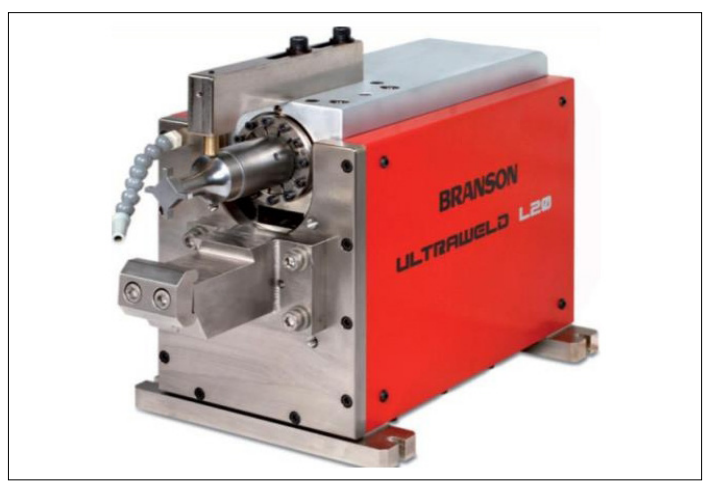

Figure 2. Schematic figure of applied spot welder. 
plate with the dimensions indicated in Figure 3.

The mechanical properties of the stainless steel X5CrNi8-10 (1.4301) used are: hardness $216 \mathrm{HB}$, conventional yield strength $\mathrm{R}_{\mathrm{p} 0,2}=190 \mathrm{MPa}$, The tensile strength is $\mathrm{R}_{\mathrm{m}}=500-700 \mathrm{MPa}$, and the electrical conductivity is $0,73 \mathrm{~m} /\left(\Omega \cdot \mathrm{mm}^{2}\right)$.

The applied CW024A (Cu-DHP 2.0090) copper plate is characterized by its good formability, excellent electrical conductivity [56-58 $\left.\mathrm{m} /\left(\Omega \cdot \mathrm{mm}^{2}\right)\right]$ and good corrosion resistance, tensile strength $\mathrm{R}_{\mathrm{m}}=240 \mathrm{MPa}$, conventional yield strength $\mathrm{R}_{\mathrm{p} 0,2}=180 \mathrm{MPa}$, hardness 65-95 HB.

We made a complex experimental sequence on the basis of the literature [6, 7]. First, the results obtained as a function of the welding time parameter were analyzed, and then the amplitude was finally obtained according to the main loading force. After achieved the highest tensile force results, it was made a correction measurement to validate the parameters to earn true final results. The evolution of the parameters is shown in the following two diagrams (Figures 4 and 5).

The trigger pressure and the welding pressure unit is MPa which means the pressure in the pneumatique cilinder of the welder machine. The measurements showed a standard deviation of $7 \%$ in each test, which can be considered acceptable for ultrasonic welding.

It was interesting to observe that although the thermal conductivity of the materials is very good, heat and stress collection sites visible with a thermal imager are formed, although these sites are not formed in the immediate vicinity of the welding point. This can be seen in Figure 6 .

Trial welds were performed to determine the ultrasonic welding parameters of the copper-austenitic stainless steel mixed bond.

In our studies, we found that the best parameter combination for the formation of the bond was the parameters in Table 1. for the steel and copper used.

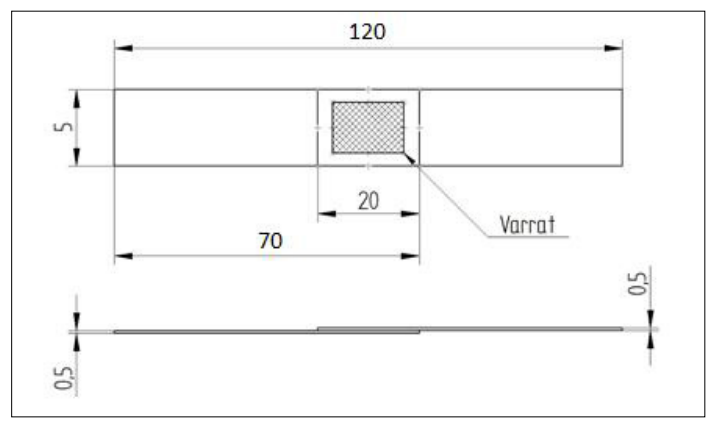

Figure 3. Schematic illustration of the test piece.

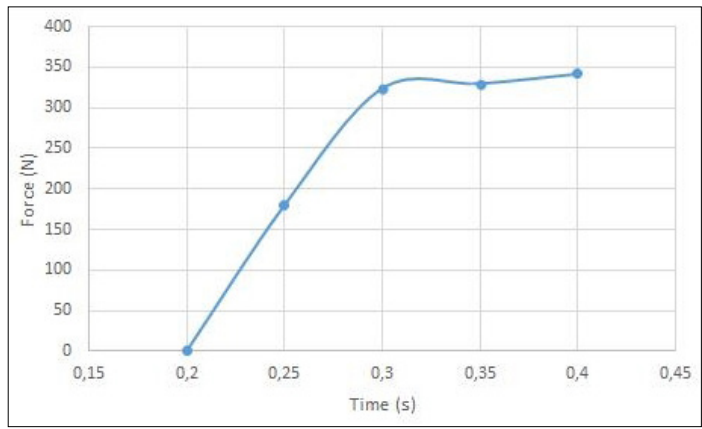

Figure 4. Tensile strength as a function of welding time (other parameters: amplitude: $50 \mu \mathrm{m}$; T.P/W.P: 0,345 MPa)

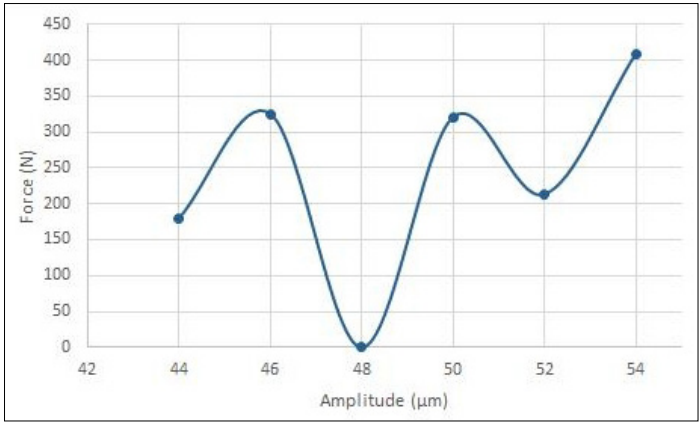

Figure 5. Tensile strength as a function of amplitude (other parameters: time: 0.3 s; T.P/W.P: 0,3 $\mathrm{MPa}$ )

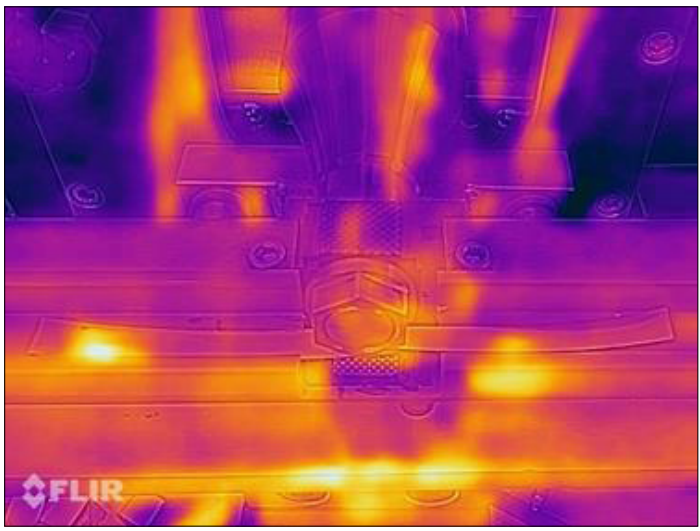

Figure 6. Thermal camera image of ultrasonic spot welding

Table 1. Parameters of ultrasonic welding

\begin{tabular}{|l|c|}
\hline \multicolumn{1}{|c|}{ Parameters } & Value \\
\hline $\begin{array}{l}\text { Welding(W.P.) and trigger(T.P) } \\
\text { pressure }\end{array}$ & $0.345 \mathrm{MPa}$ \\
\hline Time & $0.3 \mathrm{~s}$ \\
\hline Amplitude & $50 \mu \mathrm{m}$ \\
\hline
\end{tabular}




\section{Conclusion}

Based on the results of the experiments, it can be said that ultrasonic welding technology can be used to combine materials with different melting points with good results. The formation of the joint between the tested copper and steel quality plates are suitable because they are not torn in the joint under the shear-tensile test.

The suggested welding parameters for stainless steel and copper ultrasonic welding to earn the suitable joint with Branson welder machine are the next: welding time $0.3 \mathrm{~s}$, amplitude $50 \mu \mathrm{m}$, Trigger pressure and welding pressure also $0.345 \mathrm{MPa}$.

\section{References}

[1] Bagyinszki Gy., Bitay E.: Hegesztéstechnika II. Berendezések és mérések. Műszaki Tudományos Füzetek 10., EME, Cluj, 2010. https://doi.org/10.36242/mtf-09
[2] Bagyinszki Gy., Bitay E.: Hegesztéstechnika I. Eljárások és gépesités. Műszaki Tudományos Füzetek 9., EME, Cluj, 2010. https://doi.org/10.36242/mtf-08

[3] Woo J.: A short History of the development of Ultrasound in Obstetrics and Gynecology. Pierre Curie. (accessed on: 2019. 04. 15.) http://www.ob-ultrasound.net/curie.html

[4] Wu X., Liu T., Cai W.: Microstructure, Welding Mechanism, and Failure of $\mathrm{Al} / \mathrm{Cu}$ Ultrasonic Welds. Journal of Manufacturing Processes, 20/1. (2015) 321-331. https://doi.org/10.1016/j.jmapro.2015.06.002

[5] Astashev V. K., Babitsky V. I.: Ultrasonic Processes and Machines, Dynamics, Control and Applications. Springer-Verlag Berlin and Heidelberg, 2007, 33-45.

[6] Callister W. D., Rethwisch D. G.: Materials science and engineering an introduction, $8^{\text {th }}$ ed., John Wiley\&Sons, Inc. USA, 2000. 219-222.

[7] Chen K., Zhang Y.: Mechanical analysis of ultrasonic welding considering knurl pattern of sonotrode tip. Materials and Design, 87/5. (2015) 393-404. https://doi.org/10.1016/j.matdes.2015.08.042 